\title{
Modern Problems of Gasification of Coal Fuels (Brief Overview)
}

\author{
Alexander Yu. Radzyuk*, Elena B. Istyagina, \\ Vladimir A. Kulagin and Andrey V. Zhuikov \\ Siberian Federal University \\ Krasnoyarsk, Russian Federation
}

Received 15.06.2021, received in revised form 24.07.2021, accepted 10.08.2021

\begin{abstract}
The analysis of literary sources in the field of gasification of water-coal fuel is presented. The results of theoretical studies of the physicochemical laws of gasification and determination of the most expedient operating parameters based on the calculated composition of synthesis gas using a mathematical model of heat and mass transfer processes occurring with a moving fuel particle in the volume of the gas generator are considered. Comparison of theoretical and theoretical and experimental data of the process of low-temperature gasification of water-coal fuel on air and oxygen blast, demonstrating the adequacy of this model. Conclusions are made about the main advantages and disadvantages of using this method of coal combustion. It is shown that one of the most promising technologies for the energy use of coal is the preparation of coal-water suspensions, which are composite liquid fuel with predetermined technological and rheological properties to ensure minimum operating costs during its preparation, storage, transportation, combustion or gasification. The main results of work on the cavitation treatment of a coal-water suspension and fuel preparation obtained by the authors of the articles are presented.
\end{abstract}

Keywords: coal, suspension, water-coal fuel, combustion, gasification, cavitation treatment, storage, transportation, fuel preparation.

Citation: Radzyuk A. Yu., Istyagina E. B., Kulagin V. A., Zhuikov A. V. Modern problems of gasification of coal fuels (brief overview), J. Sib. Fed. Univ. Eng. \& Technol., 2021, 14(5), 487-506. DOI: 10.17516/1999-494X-0328

(C) Siberian Federal University. All rights reserved

This work is licensed under a Creative Commons Attribution-Non Commercial 4.0 International License (CC BY-NC 4.0).

* Corresponding author E-mail address: aradzyuk@sfu-kras.ru 


\title{
Современные проблемы газификации
}

\section{водоугольного топлива (краткий обзор)}

\author{
А.Ю. Радзюк, Е. Б. Истягина, \\ В.А. Кулагин, А.В. Жуйков \\ Сибирский федеральный университет \\ Российская Федерачия, Красноярск
}

\begin{abstract}
Аннотация. Изложен анализ литературных источников в области газификации водоугольного топлива. Рассмотрены результаты теоретических исследований физико-химических закономерностей газификации и определения наиболее целесообразных режимных параметров на основе рассчитанного состава синтез-газа с использованием математической модели тепломассообменных процессов, происходящих с движущейся частицей топлива в объеме газогенератора. Проведено сравнение расчетно-теоретических и экспериментальных данных процесса низкотемпературной газификации водоугольного топлива на воздушном и кислородном дутье, демонстрирующее адекватность данной модели. Сделаны выводы об основных достоинствах и недостатках применения такого способа сжигания угля. Показано, что одной из наиболее перспективных технологий энергетического использования угля является приготовление водоугольных суспензий, которые представляют собой композиционное жидкое топливо, обладающее заранее заданными технологическими и реологическими свойствами для обеспечения минимальных эксплуатационных затрат при его приготовлении, хранении, транспортировании, сжигании или газификации. Приведены основные результаты работ по кавитационной обработке водоугольной суспензии и топливоподготовке, полученные авторами.
\end{abstract}

Ключевые слова: уголь, суспензия, водоугольное топливо, сжигание, газификация, кавитационная обработка, хранение, транспортирование, топливоподготовка.

Цитирование: Радзюк, А. Ю. Современные проблемы газификации водоугольного топлива (краткий обзор) / А. Ю. Радзюк, Е.Б Истягина, В. А. Кулагин, А. В. Жуйков // Журн. Сиб. федер. ун-та. Техника и технологии, 2021, 14(5). С. 487-506. DOI: $10.17516 / 1999-494 X-0328$

\section{Введение}

Необходимость решения таких задач, как утилизация отходов угле- и нефтепереработки, снижение концентраций опасных антропогенных выбросов оксидов серы и азота, а также углекислого газа, повышение пожаро- и взрывобезопасности технологических процессов угольной энергетики, обусловила развитие фундаментальных теоретических и экспериментальных исследований в области поиска новых энергетических топлив.

В качестве замены традиционных энергетических топлив в последнее время все чаще предлагается использовать водоугольное топливо (ВУТ) как в виде водоугольных суспензий (BУC), так и в виде более сложных многокомпонентных композиций, например органоводоугольных топлив (ОВУТ) - композиционных топлив на базе угля с добавлением жидкого горючего компонента (масла, типичных отходов нефтепереработки, смол). Исследования, направленные на изучение особенностей их приготовления, транспортировки и технологий сжигания, активно развиваются [1-11].

Проблемам использования, подготовки, транспортировки ВУТ посвящен обзор [12]. Автор дает всестороннюю оценку состояния проблемы, анализирует зарубежные и отечественные публикации по теме, подробно останавливаясь на перспективах использования ВУС для 
котельных, мазутных ТЭС, газогенераторных установок и двигателей внутреннего сгорания. В работе сделан вывод, что по мере достижений в развитии уровня современных технологий разработки по тематике угольных суспензий будут востребованы по технологическим, экономическим и экологическим показателям.

При использовании любых топлив большой интерес представляет определение необходимых и достаточных условий для инициирования устойчивого сжигания топлива, определяемых рядом факторов: компонентный состав, дисперсность твердой фазы, а для водоугольного органического топлива - вязкость и ее зависимость от скорости и температуры транспортирования, стабильность суспензии, содержание химических добавок, содержание и состав минеральных примесей, включая такие экологически вредные, как соединения серы и другие токсичные вещества.

Определение свойств суспензионного топлива в зависимости от содержания влаги, характеристик угля и степени его грануляции приведено в работе [1]. Разработанная математическая модель горения водоугольной суспензии содержит уравнения, учитывающие явления, сопровождающие горение суспензионного топлива в различных условиях, и удовлетворительно согласуется с экспериментальными результатами, полученными при горении водоугольной взвеси на воздухе и в псевдоожиженном слое.

Одним из новых способов создания ВУС является способ, основанный на гидродинамических кавитационных эффектах [13-23]. Сжигание ВУС на основе канско-ачинских бурых углей показало увеличение скорости сгорания топлива, что подтверждает перспективность внедрения его предварительной кавитационной обработки.

\section{Накопленный опыт приготовления и применения ВУС}

Идея использования варианта углепереработки с получением жидкого топлива на основе угля не нова и была реализована неоднократно [24-58]. Основным критерием при выборе способов приготовления ВУС для использования ее для выработки энергии в теплотехнологических аппаратах без предварительной подготовки является получение суспензии с приемлемыми для гидротранспорта и устойчивого сжигания свойствами. Достижение необходимых параметров возможно ограниченным количеством воздействий: обеспечением на стадии приготовления точно подобранного гранулометрического состава ВУС; введением химических добавок (с водой, на стадии измельчения топлива, в готовую суспензию); обеспечением турбулентного режима течения в гидропроводе; активацией суспензии в различных гидродинамических аппаратах (в месте приготовления, на стадиях перекачки, при транспорте, хранении) и некоторых других (подогрев, подгазовка и пр.).

Хранение, подача и сжигание ВУС в терминале углепровода Белово-Новосибирск [45]. Конечный пункт углепровода (терминал) был размещен в цехе гидроугля и по технологическому признаку может быть условно разделен на три составные части: системы приема, хранения и подачи.

Система приема ВУС включает ловушку «ерша», узел разрывных мембран, линейный нагреватель, два резервуара, аварийный резервуар перелива, насосы перелива. Ловушка «ерша» служит для приема очистительных скребков. Имеется возможность отключить ее от трубопровода и извлечь скребок без остановки углепровода. Узел разрывных мембран рассчитан

$$
-489-
$$


на защиту углепровода от давления выше 1,8 МПа. Линейный нагреватель, включающий три последовательно соединенных теплообменника 800ТКГ-25-66-0-25-6-1 гр.3, позволяет нагревать поступающую ВУС не менее чем до $12{ }^{\circ} \mathrm{C}$.

Суспензия поступает в два резервуара объемом 20000 м³ $^{3}$ каждый. При переполнении резервуаров излишки ВУС сливаются в аварийный резервуар объемом $100 \mathrm{~m}^{3}$, дающий возможность в течение $0,5-1,0$ ч разрешить аварийную ситуацию. Насосами перелива суспензия возвращается из аварийного резервуара в резервуары хранения ВУС.

Система хранения включает резервуары с мешалками, насосы рециркуляции и нагреватель системы рециркуляции. Нагреватель, включающий три последовательно соединенных теплообменника, служит для подогрева находящейся в резервуарах ВУС в холодное время года. Прокачивание суспензии через теплообменник производится двумя центробежными насосами фирмы «Варман», каждый из которых обеспечивает подачу 200 м³/ч ВУС под давлением 0,6 МПа. Каждый резервуар оснащен четырьмя лопастными мешалками для периодического перемешивания хранящейся ВУС.

Система подачи ВУС к форсункам котла включает насосы подачи и фильтры ВУС. Для котла № 3 суспензия подается тремя винтовыми насосами фирмы «Черпелли» и фильтром фирмы «Фильтрекс». Винтовой насос обеспечивает подачу до 75 м³/ч ВУС под давлением до 2,5 МПа. На номинальном режиме работы котла подача топлива производится двумя насосами, а третий находится в резерве. Подача ВУС регулируется тиристорным преобразователем, изменяющим частоту переменного тока, подаваемого на асинхронный электродвигатель привода насоса. Фильтр имеет перфорированную поверхность, рассчитанную на улавливание частиц размером более 3 мм. Система подачи ВУС на остальные котлы оборудована поршневыми насосами НБ-125 и фильтром, отличительной особенностью которого является постоянная очистка фильтрующей поверхности вращающимися скребками.

Системы приема, хранения и подачи ВУС оборудованы трубопроводами для подвода технической воды и дренажной системой для отвода воды после промывки оборудования.

Первая партия ВУС, поступившая по углепроводу, имела концентрацию угля более 55 \%, вязкость около 0,5 Па·с при скорости сдвига $9 \mathrm{c}^{-1}$ и низкую седиментационную устойчивость. Эти обстоятельства привели к необходимости использовать мешалки резервуаров в режиме 50\%-ного включения. Но даже и в этом случае наблюдалось образование осадка.

Контур рециркуляции оказался достаточно надежным. В зимнее время теплообменники обеспечили нагрев ВУС с большим запасом. Также надежны в работе были центробежные насосы рециркуляции. Некоторые сложности в их эксплуатации связаны с работоспособностью узла уплотнения вала и образованием осадка в данной части корпуса при остановке более чем на 12 ч, что вызывало затруднения с запуском насоса.

По данным испытаний, затраты энергии при непрерывном перемешивании ВУС в резервуаре составляют около 0,002 кВт/м³. В режиме включения разного количества мешалок и изменения периодичности их включения изменяется удельный расход электроэнергии, причем при периодическом включении потребляется электроэнергии на 10-25 \% больше, чем при непрерывном, что происходит из-за сгущения ВУС и увеличения крутящего момента импеллера мешалки. Учитывая весьма невысокие энергозатраты на перемешивание, необходимо оптимизировать гидравлическую схему струйного перемешивания, чтобы исключить 
застойные зоны в резервуарах и уменьшить износ самой мешалки и узла двойного торцевого крепления.

Крупномаситабные эксперименты по приготовлению и сжиганию ВУС на котле паропроизводительностью 320 m/ч Беловской ГРЭС [45-47]. Принципиальная схема узла опытнопромышленной установки по хранению, подаче и сжиганию ВУС включает в себя емкость для хранения, насосы, фильтры, теплообменники, котел, форсунки, встроенные в горелки, аппаратуру для управления потоками ВУС внутри цеха. Согласно схеме приготовленная ВУС направлялась в аккумулирующую емкость, где накапливалась в резервуаре емкостью $450 \mathrm{~m}^{3}$; по мере готовности суспензия подавалась небольшими порциями с температурой $37-47^{\circ} \mathrm{C}$. Из-за дискретной подачи нижние слои суспензии в процессе хранения охлаждались, и поэтому, чтобы исключить послойное осаждение частиц угля, холодные и теплые слои жидкости периодически перемешивались с помощью насоса, подключенного к малому контуру рециркуляции. Это позволяло сохранить стабильной и устойчивой структуру ВУС в течение 1-2 мес.

Приготовленная в шаровой и стержневой мельницах мокрого помола с добавкой ПАВ типа НФУ водоугольная суспензия имела следующие характеристики: фракционный состав твердых угольных частиц в смеси $R_{90}=28-35 \% ; R_{200}=10-12 \%$, плотность $\rho=1180-1220$ кг $/ \mathrm{M}^{3}$, коэффициент динамической вязкости $\eta=8-10$ Пз при температуре 290 К и $\eta=5-6$ Пз при температуре 320 К [45].

Для отработки технологии очистки промывочных вод были проведены соответствующие исследования, измерялись расходы промывочной воды и время промывки оборудования, а через равные промежутки времени - концентрация частиц угля и диспергатора (химические добавки). Промывка завершалась по достижении концентраций загрязнений, удовлетворяющих требованиям правил сброса сточных вод. При испытаниях были опробованы сорбционный, флотационный, седиментационный и механический способы очистки вод. По результатам исследований была выбрана технология очистки с предварительным отстаиванием и сгущением взвеси в тонкослойных отстойниках с периодическим сливом очищенной воды. Сгущенную часть пульпы было рекомендовано подавать для сжигания в топке котла.

Подача ВУС к котлу осуществлялась центробежным углесосом $10 \mathrm{Y} 4$ производительностью 97,4 кг/с. В период проведения опытных работ согласно программе исследований было приготовлено и сожжено около 6000 т ВУС из кузнецких углей марок Д и Г и отработаны режимы работы оборудования по приготовлению суспензии подбором химических добавок, изучены седиментационная устойчивость и реологические характеристики готовой ВУС [45-47]. Первые опытные партии ВУС в процессе наладки и отработки режимов системы ее приготовления содержали крупные частицы угля и инородных предметов. Это потребовало создания и установки в тракте подачи ВУС специального роторного фильтра с электроприводом для периодической очистки фильтрующих элементов.

Технологию получения ВУС из бурых углей отрабатывали на опытно-промышленной установке на Ачинском глиноземном комбинате (АГК). На базе имеющегося размольного оборудования в экспериментальном цехе АГК была смонтирована технологическая линия по производству ВУС производительностью от 4 до 21 т/ч.

Показано, что наиболее эффективными для промышленного производства суспензий являются последовательно включенные шаровая и цильпебсная мельницы, причем изготовление

$$
-491-
$$


1 т суспензии по схеме двухстадийного помола в этих мельницах энергозатраты не превышают 25 кВт/ч [48].

Технология приготовления жидкого композитного топлива на базе торфяного геля разработана в «Проблемной лаборатории теплоэнергетики при НГТУ» [33]. Сущность технологии заключается в следующем: предварительно измельченный торф подают в емкость для приготовления коллоидной смеси, в эту же емкость подают воду. Воду и торф смешивают в заданном соотношении при условии, что содержание жидкой фазы в коллоидной смеси должно быть не менее 15 \% по объему. После предварительного смешения в емкости торфоводяной раствор направляют в диспергатор-кавитатор, где осуществляют окончательный размол торфа с образованием коллоидной смеси заданного качества. Регулирование процесса осуществляют кратностью обработки смеси путем организации соответствующей обратной связи и интенсивностью обработки в диспергаторе-кавитаторе (например, регулированием числа оборотов двигателя для диспергатора-кавитатра ротационного типа).

Аналогичным образом готовят водоугольную суспензию. Воду и уголь смешивают в заданном соотношении при условии, что содержание жидкой фазы в водоугольной суспензии должно быть не менее 15 \% по объему. Затем путем обработки в диспергаторе-кавитаторе получают суспензию заданного качества.

Жидкое композитное топливо получают путем предварительного смешения жидкого топлива (например, нефти или мазута), коллоидной смеси и водоугольной суспензии в собственной емкости с последующей обработкой в диспергаторе-кавитаторе аналогично приготовлению коллоидной смеси и угольной суспензии. Готовое жидкое композитное топливо направляют в емкость, откуда насосом подают на горелочные устройства котлоагрегата.

Таким образом, в предложенной технологии за счет вариации компонентов, интенсивности обработки каждого компонента и композитного топлива в целом получают жидкое топливо заданного качества (например, с заданной теплотой сгорания, зольностью, сернистостью, температурой воспламенения и т. п. или совокупностью этих свойств) вне зависимости от изменяющихся свойств компонентов. Полученное топливо имеет глубоко диспергированный состав с размером твердой фракции менее 35 мкм. Такое топливо может быть использовано как в качестве основного топлива, так и в качестве растопочного. В то же время при незначительных изменениях технологической линии приготовления топлива можно получать торфоугольный брикет или гранулы для слоевого сжигания (в том числе и в кипящем слое).

Зарубежный опыт приготовления топливных суспензий. В США исследовательские работы по созданию методов использования высокообводненного топлива для энергетических целей были начаты в середине 1950-х гг., а в 1957 г. был введен в действие первый в мире гидротранспортный комплекс «Кадис - Ист Лэйк» (протяженностью трубопровода 173 км и мощностью 1, 25 млн т в год), а затем и «БлэкМэса-Мохейв» (439 км, 4, 6 млн т в год), работающие по следующей технологии: измельченный уголь смешивается с водой (содержание твердой фазы 46-48 \%, средняя зольность 9,8 \%) и в турбулентном режиме со скоростью 1,5-1,7 м/с подается на конечный терминал - потребителю. Там он обезвоживается, осушается и поступает в котлы для сжигания. Значительный объем работ по созданию водоугольной суспензии был выполнен в это же время в ФРГ, Японии, Польше [56, 57].

$$
-492-
$$


На втором этапе во многих странах развитие работ по водоугольным суспензиям было обусловлено разразившимся в середине 1970-х гг. нефтяным кризисом. Были развернуты работы по приготовлению, транспортированию и сжиганию водоугольных суспензий с целью изучения возможности замены ими дорогостоящей и дефицитной нефти и нефтепродуктов [52, 53].

Максимальное привлечение фирм, корпораций, университетов и промышленных предприятий к работам в области водоугольных суспензий относится к 1979-84 гг., когда вопросами приготовления, хранения, транспорта и сжигания ВУС занималось более ста организаций в США, Швеции, Великобритании, Китае, Японии, Канаде, Италии и других странах. В этот период возникли такие известные международные корпорации, как «Carbogel» и «Fluidcarbon» (Швеция). В результате за рубежом были созданы и проверены в промышленных условиях разнообразные технологии приготовления водоугольных суспензий: Densecoal (ФРГ) [53], Reocarb (Италия) [51], Carbogel [54] и Fluidcarbon (Швеция) [55], топливо CWM («Джапан Ком компани», Япония) [51] и др.

\section{Особенности сжигания водоугольных суспензий}

Результаты экспериментальных исследований процесса воспламенения капель многокомпонентных водоугольных суспензий на основе длиннопламенного угля с добавкой жидких продуктов пиролиза резиновых отходов приведены в работе [59]. Представлены экспериментальные результаты определения стабильного времени задержки воспламенения одиночных капель жидких многокомпонентных топливных композиций на основе угля и жидкой фракции продуктов пиролиза резиновых отходов. Проанализировано влияние массовой доли жидкой фракции продуктов пиролиза резиновых отходов в составе водоугольной суспензии на стабильное время задержки воспламенения одиночных капель топлива.

Пороговые условия воспламенения топливных суспензий, полученных из отходов переработки угля с растительными маслами (рапсовое, касторовое) и отработанными маслами на нефтяной основе, в момент их воспламенения в высокотемпературной неподвижной воздушной среде приведены в работе [60]. На базе полученных результатов сформулирована гипотеза о физическом механизме разрушения капель композиционного топлива в условиях воспламенения и влиянии состава компонента на дробление капель при воспламенении.

Свойства топлив, влияющие на процесс тепломассопереноса при нагревании и воспламенении, - это зольность, влажность, выход летучих, температура разложения и температура воспламенения компонентов смеси. В работе [61] сравниваются характеристики сжигания топливной суспензии с характеристиками сжигания угля и мазута, доказываются экологические преимущества их использования по сравнению с использованием традиционных видов топлива на тепловых электростанциях с точки зрения сокращения выбросов $\mathrm{NO}_{\mathbf{x}}$ и $\mathrm{SO}_{\mathrm{x}}$, масштабного сокращения складирования отходов и минимизации ресурсозатрат. Разработка технологий использования данных видов топлива позволит помимо получения энергии решить проблему утилизации отходов угле- и нефтепереработки.

Изучению влияния свойств ОВУТ на режим горения топлива посвящена работа [62], в которой описываются три режима горения, зависящие от зольности, выхода летучих веществ, а также от температур воспламенения и горения используемых нефтепродуктов. По результа- 
там экспериментов установлены диапазоны изменения температуры воздуха, характерные для каждого из трех режимов горения топливных суспензий.

Использование композитных жидких топлив на основе угледобывающих, нефтеперерабатывающих и других отходов, а также биомассы способствует их утилизации в энергетическом цикле. В работе [63] предлагается алгоритм расчета золы от сгорания фиксированной массы топлива. Анализ остатков золы подтвердил экологические преимущества топливных суспензий по сравнению с углем.

Экспериментально исследуется зольный остаток, образующийся при горении отдельных капель органического водоугольного топлива при различных температурах в потоке окислителя (горячего воздуха) и в работе [64]. Определяется масса компонентов зольного остатка и его элементарный состав в зависимости от температуры окислителя и состава органической составляющей топлива.

Изучение необходимых и достаточных условий для инициирования устойчивого сжигания ВУТ И ОВУТ с наиболее типичными компонентными составами способствует оптимизации работы многих электростанций и агрегатов. Экспериментальное исследование влияния компонентного состава водоугольного органического топлива на характеристики воспламенения капли в потоке окислителя рассматривается в работе [56]. Найдены времена задержки воспламенения и полного сгорания капель органического водоугольного топлива, выявлены граничные условия устойчивого воспламенения капель органического водоугольного топлива различного состава.

В работе [65] проведено сравнение характеристик воспламенения и горения водоугольного и органического водоугольного топлива. Определено влияние воды в составе композиционных угольных топлив на энергетические характеристики их воспламенения и горения, а также экологические особенности этих процессов. Рассмотрены актуальные проблемы, связанные с измельчением композитных угольных топлив на электростанциях, также влияние характеристик процесса измельчения на параметры сгорания топлива. На основании проведенного анализа авторами сделан вывод о преимуществах использования ОВУТ в качестве топлива для электростанций по сравнению с обычным водоугольным топливом (ВУТ).

Исследованию влияния на характеристики зажигания и горения ВУТ на основе воды различного качества (технической, водопроводной, дистиллированной) в потоке нагретого окислителя (при 700-1000 К) посвящена работа [66]. Полученные результаты нашли свое развитие в работах $[67,68]$ при разработке моделей горения водоугольного топлива и органического водоугольного топлива, приготовленного на основе кокса и полукокса, а также обычных нефтепродуктов (мазута и отработанного компрессорного, турбинного и трансформаторного масел). Авторы рассматривают влияние различных факторов (размера капель, температуры окислителя и концентрации компонентов) на пороговую (минимальную) температуру и инерцию воспламенения. Исследование процессов горения угольно-водонефтяных суспензий, состоящих из смеси воды с горючими твердыми и жидкими компонентами, не только предлагает средство утилизации отходов, но и расширяет топливную базу энергетических компаний.

Использование ВУС в двигателях внутреннего сгорания по совокупному тепловому эффекту экономически перспективно. В работе [69] выполнено технико-экономическое исследование производства водоугольной топливной суспензии для двигателей внутреннего сгорания. 
Проблемы, которые встречаются при использовании ВУС в качестве топлива в ДВС, - это ультратонкое измельчение угля и, самое главное, его деминерализация до остаточной зольности менее 0,5 \%. Использование новейших технологий в этой области делает суспензионное топливо конкурентоспособным с нефтяным.

Возможности использования ВУТ описываются в работе [70], где приведена полупромышленная установка сжигания водоугольного шламового топлива. Технологию приготовления ВУС можно охарактеризовать как простую с низкими эксплуатационными расходами. Проведенные экспериментальные исследования горения в котле с вихревой топкой показали высокую эффективность предлагаемого способа и обеспечение энергоэффективности котла не менее 80 \%. Предлагается использовать данную технологию сжигания ВУТ на существующем котельном заводе или при строительстве мини-ТЭЦ на ВУТ для обеспечения потребностей Тугнуйского рудника в электрической и тепловой энергии.

Определенный опыт применения ВУТ на тепловых станциях накоплен в Китае. Промышленное использование ВУТ в тепловой котельной малой мощности в котлах с псевдоожиженным слоем описано в работах [71,72]. При использовании котла по этой технологии были показаны хорошие характеристики, такие как высокий КПД, низкий уровень выбросов загрязняющих веществ, хорошее регулирование нагрузки, хорошая адаптивность к качеству CWS, стабильная работа и удобство обслуживания. Водоугольное топливо может сжигаться чисто, стабильно и с минимальным расходом, что подтверждает перспективность данной технологии.

\section{Результаты исследований \\ в области газификации водоугольного топлива}

Проблема утилизации отходов, содержащих органическую часть, стоит перед муниципальными образованиями Енисейской Сибири особенно остро. Одним из перспективных путей решения данной проблемы является утилизация отходов путем их сжигания, однако прямое сжигание отходов, в том числе и с использованием максимально эффективных из существующих методов очистки продуктов сгорания, приведет к существенному росту негативного воздействия на окружающую среду и неблагоприятной социальной реакции. Альтернативой сжигания может стать комплексная термическая переработка, включающая процессы пиролиза и газификации и позволяющая получать на выходе потребительские продукты, твердое топливо и электрическую энергию.

Основная цель газификации заключается в получении синтез-газа, пригодного для конверсии углеводородов. Энергетическая сущность газификации состоит в том, что исходную калорийность топлива накапливают в окиси углерода и водороде, т. е. твердое топливо переводится в газообразное со значительным сохранением теплотворной способности, а ее экологичность заключается в том, что сложные органические соединения, опасные для окружающей среды, переводятся в простые и безопасные, процессы горения идут в восстановительной атмосфере водорода и окиси углерода, благодаря чему не образуются диоксины и окислы азота.

В основу классификации способов газификации могут быть положены различные принципы. По состоянию топлива в газогенераторе различают способ газификации в неподвижном слое или в медленно опускающемся слое твердого топлива, газификацию в кипящем слое, газификацию в потоке пылевидного топлива. Другая классификация основана на различии спо-

$$
-495-
$$


собов подвода тепла к реактору газификации. По этой классификации различают процессы автотермические и аллотермические.

По состоянию топлива в газогенераторе:

- газификация в неподвижном слое;

- газификация в медленно опускающемся слое твердого топлива;

- газификация в кипящем слое;

- газификация в потоке пылевидного топлива.

По способам подвода тепла к реактору газификации:

- $\quad$ автотермический - необходимое для газификации тепло получают путем сжигания части введенного топлива в присутствии кислородсодержащих газифицирующих агентов;

- $\quad$ аллотермический - тепло подводится извне с помощью твердого или газообразного теплоносителя.

По принципу организации потока:

- мелкозернистый или пылевидный уголь газифицируют при подаче в одном направлении угля и газообразного газифицирующего агента;

- процесс газификации проводят в неподвижном слое.

Одной из наиболее перспективных технологий энергетического использования угля является приготовление водоугольных суспензий, которые представляют собой композиционное жидкое топливо, обладающее заранее заданными технологическими и реологическими свойствами для обеспечения минимальных эксплуатационных затрат при его приготовлении, хранении, транспортировании, сжигании или газификации.

Водоугольное топливо является на сегодняшний день перспективным энергоресурсом как в плане замены жидкого котельного топлива - мазута, так и в качестве альтернативы природному газу. Для получения газа необходима термическая переработка ВУТ - газификация.

Преимущества использования ВУТ для газификации отмечаются рядом авторов [73-78]. Среди преимуществ такие, как:

- полное сгорание капель ВУТ повышает эффективность сгорания топлива и снижает выбросы вредных веществ в атмосферу по сравнению с углем или мазутом;

- удобство транспортировки;

- возможность приготовления с использованием воды, загрязненной органикой, смолами, нефтепродуктами и другими отходами, с полной очисткой возвратной воды и использованием полученных отходов;

- повышение экономической и экологической эффективности систем теплоэнергетики;

- возможность использования низкосортных углей и углеотходов при изготовлении водоугольного топлива;

- взрыво- и пожаробезопасность на всех технологических стадиях приготовления и транспортировки;

- снижение расхода окислителя в процессе газификации; рациональные пропорции угля и воды в составе топлива создают оптимальные условия для получения газа;

- отсутствие потребности сушки угля с ее высокими энергозатратами;

- снижение потребности кислорода в процессе газификации;

- возможность безотказной автоматизации процесса подачи водоугольного топлива. 
К современным наиболее востребованным технологиям переработки углей относится прямоточная газификация водоугольных суспензий с сухим шлакообразованием. Это один из наиболее эффективных способов использования низкокалорийных высокозольных углей. Вопросам применения этого способа в последние годы было посвящено большое количество работ, наиболее интересные из них касаются разработки эффективных технологических схем.

В [78] предложена конструкция кольцевого котла, совмещенного с газификатором, в котором в качестве газифицируемого топлива используется кавитационное жидкое топливо (КЖТ), приготовленное из каменного угля. Применение КЖТ обусловливается преимуществами при транспортировке, дешевизной, если его приготавливать из отходов углеобогащения или нефтепереработки (нефтяного кокса). Критерием эффективности работы установки выступает эксергетический КПД, величина которого по сравнению с традиционной схемой выше.

В работе [79] предлагается использовать лазерное излучение для адресной доставки тепловой энергии к порции топлива. В случае лазерной газификации присутствие воды резко снижает паразитный выброс частиц вещества, возникающий при взаимодействии мощных лазерных импульсов с поверхностью топлива. Определены оптимальные режимы энергетической накачки, позволяющие максимизировать выход горючих газов $\left(\mathrm{CO}, \mathrm{H}_{2}\right)$ при минимуме вредных выбросов $\left(\mathrm{SO}_{2}, \mathrm{NO}\right)$.

Использование эксергетического метода термодинамического анализа технологической схемы конкретного энергетического объекта с целью выявления ее эффективности приводится в [80]. Газификация ВУТ на базе кузнецкого угля осуществляется под давлением в потоке воздуха. Полученный генераторный газ сжигается в ГТУ.

Анализ составов выхода зольных уносов и шлаков при газификации ВУС, приготовленных из углей «Березовский» Канско-Ачинского и «Моховский» Кузнецкого бассейнов, рассматривается в [75]. Предлагаются перспективные направления использования зольных уносов шлаков при строительстве автомобильных дорог и в производстве золоцемента.

Проблему использования технологии поточной автотермической газификации в закрученном потоке для водоугольного топлива рассматривают авторы работы [77]. Предложенный подход обеспечивает высокую интенсивность процесса и высокую степень конверсии углерода. Реализацию процесса газификации ВУТ предлагается осуществлять в циклонном двухкамерном газификаторе. С целью определения основных параметров процесса газификации проводятся исследования газификации водоугольного топлива (уголь 70 \%, вода 29 \%, реагент-пластификатор 1 \%) при воздушном и кислородном дутье.

Исследовано влияние коэффициента расхода окислителя на температурный режим процесса газификации и образование восстановительных $\left(\mathrm{CO}\right.$ и $\left.\mathrm{H}_{2}\right)$ и окислительных $\left(\mathrm{CO}_{2}\right.$ и $\left.\mathrm{H}_{2} \mathrm{O}\right)$ компонентов генераторного газа при воздушной и кислородной газификации водоугольного топлива. Технологические решения при производстве и газификации ВУС кардинальным образом сказываются на его теплоэнергетических свойствах.

Эффективный способ использования низкосортных высокозольных углей для теплоэнергетики - это прямоточная газификация водоугольных суспензий с сухим шлакообразованием. Такая технология в масштабе опытно-промышленной установки разработана совместно ЗАО «КОМПОМВШ-ТЭК» и ФГУП ИГИ [81].

$$
-497-
$$


В первой стадии исходное угольное сырье измельчали в быстроходном частотном диспергаторе до порошка размером частиц суспензии 20-30 мкм. Затем порошок смешивали с водой с добавкой стабилизатора и обрабатывали в гидроударном аппарате с эффектом кавитационного воздействия. Полученная водоугольная суспензия была стабильна в течение 2 мес. и более. Полученное водоугольное топливо было близко по основным показателям (условная вязкость, температура застывания, содержание серы) к мазуту М-100.

Применение сухого шлакообразования при прямоточной газификации водоугольных суспензий с использованием шлака и зольных уносов позволяет упростить систему складирования шлака и утилизацию золошлаковых материалов, снизить выбросы вредных веществ в атмосферу, улучшив экологическую обстановку, обеспечить снижение расхода угля и снижение выбросов $\mathrm{CO}_{2}$ на электростанциях.

Экспериментальные исследования коэффициента теплопроводности водоугольных топлив, полученных из углей разной стадии метаморфизма, отличающихся повышенным содержанием минеральных примесей, в зависимости от размера частиц твердой фазы, а также влияние предварительной механической активации на теплотворную способность угольного вещества приведены в работе [82].

Экспериментальные данные, полученные в широком диапазоне изменения температуры, обрабатывались путем комбинирования метода сравнения и численного решения обратной задачи теплопроводности. Для обработки экспериментальных данных использована математическая модель, которая позволяет рассчитывать распределение температурных полей в нестационарном режиме. В процессе численного решения использовались граничные условия I, II, III и IV рода. Для проверки адекватности разработанной математической модели, а также для реализации метода сравнения на экспериментальной установке проведены исследования по определению коэффициента теплопроводности эталонного вещества (воды).

Исследования показали, что при приготовлении водоугольных топлив с предварительной механической активацией угольного вещества увеличивается образование промежуточных горючих газообразных соединений, что влияет на теплофизические свойства, теплотворную и реакционную способность водоугольных топлив, и интенсифицируется процесс последующей термической переработки.

Для исследования основных закономерностей процесса газификации водоугольного топлива в [76] предложена равновесная термодинамическая модель расчета характеристик и свойств гетерогенной системы с нахождением состава и свойств продуктов реакций. Выполнено сравнение расчетно-теоретических показателей процесса газификации топлива и показателей работы опытно-промышленных установок, показана адекватность данной равновесной модели. Представлены результаты исследований процесса газификации водоугольного топлива при различных режимных параметрах процесса. Получены рациональные показатели воздушной и кислородной газификации водоугольного топлива.

Здесь же проведено сравнение расчетно-теоретических и экспериментальных данных процесса низкотемпературной газификации водоугольного топлива на воздушном и кислородном дутье, демонстрирующее адекватность данной модели.

Теоретические исследования физико-химических закономерностей газификации ВУТ и определение наиболее целесообразных режимных параметров на основе рассчитанного со- 
става синтез-газа с использованием математической модели тепломассообменных процессов, происходящих с движущейся частицей топлива в объеме газогенератора, проведены в работе [78]. Разработанная математическая модель тепломассообмена между каплей ВУТ и потоком греющего газа в объеме газогенератора позволяет определить количество теплоты, необходимое для термического преобразования водоугольного топлива в синтез-газ, время пребывания капли ВУТ в реакционном объеме и длину газогенератора. В результате проведенной техникоэкономической оценки доказана экономическая эффективность бескислородной газификации ВУТ в сравнении с кислородной газификацией угля.

Исследованию реологических свойств, стабильности и характеристик горения суспензий, приготовленных на деионизированной воде и на сточной воде газификации угля, посвящена работа [83]. Результаты показали, что использование сточной воды газификации в технологии приготовления ВУТ не ухудшает энергетических характеристик топлива и выгодно с экономической и экологической точек зрения.

\section{Выводы}

Проведенный обзор публикаций позволяет сделать вывод, что глобальный рост энергопотребления в мире, а также рост цен на энергоносители за последние несколько лет обострил потребность в использовании альтернативных видов топлив. Общепризнанным трендом сегодня является все более широкое использование в энергетике горючих промышленных отходов и низкосортных топлив. Это расширяет топливную базу энергетики, а также дает возможность утилизировать накопленные за многие годы отходы угледобычи и углепереработки.

\section{Список литературы/ References}

[1] Баранова М.П., Кулагин В.А. Физико-химические основы получения топливных водоугольных суспензий / ред. В. А. Кулагин. Красноярск: ИПКСФУ, 2011. 160 с. [Baranova М.Р., Kulagin V. A. Physicochemical bases for obtaining fuel water-coal suspensions; ed. V. A. Kulagin. Krasnoyarsk: IPK SFU, 2011. 160 p. (in Russian)].

[2] Баранова М.П., Кулагин В. А., Тарабанько В.Е. Природа стабилизации и водоугольных топливных суспензий, Журнал прикладной химии, 2011, 84(6), 916-921 [Baranova M.P., Kulagin V.A., Taraban'ko V.E. The nature of stabilization of coal-water fuel suspensions, Journal of Applied Chemistry, 2011, 84(6), 916-921 (in Russian)].

[3] Кулагин В.А. Методы и средства технологической обработки многокомпонентных сред с использованием эффектов кавитащии: Дис. ... д-ра техн. наук. Красноярск, 2004. 379 c. [Kulagin V.A. Methods and means of technological processing of multicomponent media using cavitation effects: Dis. ... dr. tech. sciences. Krasnoyarsk, 2004. 379 p. (in Russian)].

[4] Радзюк А.Ю. Методы и средства подготовки водоугольной суспензии для теплотехнологических установок: Дис. ... канд. техн. наук, Красноярск, 2005. 131 с. [Radzyuk A.Yu. Methods and means of preparing a coal-water suspension for heat-technological installations: Dis. ... cand. tech. nauk, Krasnoyarsk, 2005.131 p. (in Russian)].

[5] Кулагина Т.А.Эффективность подготовительных проиессов сжсиания водотопливных смесей в топках малого объема: Дис. ... д-ра техн. наук. Красноярск, 2009. 340 с. 
[Kulagina T. A. The effectiveness of preparatory processes for the combustion of water-fuel mixtures in small-volume furnaces: Dis. ... dr. tech. sciences. Krasnoyarsk, 2009. 340 p. (in Russian)].

[6] Баранова М.П. Технология получения и использования топливных водоугольных суспензий из углей различной степени метаморфизма: Дис. ... д-ра техн. наук, Красноярск, 2014. 255 c.[Baranova M.P. Technology of obtaining and using fuel water-coal suspensions from coals of varying degrees of metamorphism: Dis. ... dr. tech. sciences, Krasnoyarsk, 2014.255 p. (in Russian)].

[7] Kulagin V.A., Kulagina L.V., Li Feng-Chen Fundamentals of Cavitation Treatment for Multi-component Environments. Moscow: Ru-science, 2017. 182 p.

[8] Мурко В.И., Джундубаев А.К., Баранова М.П., Бийбосунов А.И., Кулагин В.А. Гидротранспортные топливно-энергетические комплексы. Российско-кыргызское научно-техническое сотрудничество в области теплоэнергетики. Красноярск: Сиб. федер. ун-т, 2015. 250 с. [Murko V.I., Dzhundubaev A.K., Baranova M.P., Biybosunov A.I., Kulagin V. A. Hydrotransport fuel and energy complexes. Russian-Kyrgyz scientific and technical cooperation in the field of heat power engineering. Krasnoyarsk: Sib. Feder. un-t, 2015. 250 p. (in Russian)].

[9] Murko V., Khyamyalyainen V., Baranova M. Use of Ash-and-Slag Wastes after Burning of Fine-Dispersed Coal-Washing Wastes, E3S Web of Conferences, 2018, 41, 01042.

[10] Dmitrii O. Glushkov, Dmitrii P. Shabardin, Pavel A. Strizhak, Ksenia Yu. Vershinina, Influence of organic coal-water fuel composition on the characteristics of sustainable droplet ignition, Fuel Processing Technology, 2016, 143, 60-68.

[11] Зайденварг В.Е., Трубецкой К.Н., Мурко В.И., Нехороший И.Х. Производство u использование водоугольного топлива. М.: Изд-во Академии горных наук, 2001. 176 с. [Zaydenvarg V.E., Trubetskoy K. N., Murko V.I., Bad I. Kh. Production and use of coal-water fuel. Moscow: Publishing house of the Academy of Mining Sciences, 2001.176 p. (in Russian)].

[12] Agnieszka Kijo-Kleczkowska. Combustion of coal-water suspensions, Fuel, 2011, 90(2), $865-877$.

[13] Ходаков Г.С. Водоугольные суспензии в энергетике, Теплоэнергетика, 2007, 1, 35 45 [Khodakov G. S. Coal-water suspensions in power engineering, Teploenergetika, 2007, 1, 35-45. (in Russian)].

[14] Khodakov G.S., Gorlov E. G., Golovin G. S. Coal suspension fuel. Solid Fuel Chemistry, $2005,6,15-32$.

[15] Baranova, M.P., Kulagina, T.A. \& Lebedev, S. V. Combustion of water and coal suspension fuels of low-metamorphized coals, Chem Petrol Eng, 2009, 45, 554-557.

[16] Ивченко В.М., Кулагин В.А., Немчин А.Ф. Кавитационная технология / ред. акад. Г.В. Логвинович. Красноярск: Изд-во КГУ, 1990. 200 с. [Ivchenko V.M., Kulagin V.A., Nemchin A.F. Cavitation technology; ed. acad. G. V. Logvinovich. Krasnoyarsk: KSU Publishing House, 1990.200 p. (in Russian)].

[17] Кулагин В.А., Вильченко А.П., Кулагина Т.А. Моделирование двухфазных суперкавитационных потоков / ред. В.И. Быков. Красноярск: ИПЦКГТУ, 2001. 187 с. [Kulagin V. A., Vilchenko A.P., Kulagina T.A. Modeling of two-phase supercavitation flows; ed. V.I. Bykov. Krasnoyarsk: IPC KSTU, 2001. 187 p. (in Russian)]. 
[18] Балабышко А.М., Зимин А. И., Ружицкий В. П. Гидромеханическое диспергирование. М.: Наука, 1998. 331 с. [Balabyshko A. M., Zimin A. I., Ruzhitskiy V.P. Hydromechanical dispersion. Moscow: Nauka, 1998. 331 p. (in Russian)].

[19] Тебенихин Е.Ф., Гусев Б. Т. Обработка воды магнитным полем в теплоэнергетике. М.: Энергия, 1970. 143 с. [Tebenikhin E. F., Gusev B. T. Water treatment by a magnetic field in heat power engineering. Moscow: Energiya, 1970. 143 p. (in Russian)].

[20] Zhi-Ying Zheng, Qian Li, Lu Wang, Li-Ming Yao, Wei-Hua Cai, Vladimir A. Kulagin, Hui Li, Feng-Chen Li Numerical study on the effect of steam extraction on hydrodynamic characteristics of rotational supercavitating evaporator for desalination, Desalination, 2019, 455 1-18.

[21] Баранова М.П., Кулагина Л.В., Екатеринчев В.М. Физико-химические основы промылиленных теплотехнологий. Красноярск: Гротеск, 2018. 148 с. [Baranova M.P., Kulagina L. V., Ekaterinchev V.M. Physical and chemical foundations of industrial heat technologies. Krasnoyarsk: Grotesk, 2018. 148 p. (in Russian)].

[22] Демиденко Н.Д., Кулагин В.А., Шокин Ю. И., Ли Ф.-Ч. Тепломассообмен и суперкавитация. Новосибирск: Наука, 2015. 436 с. [Demidenko N.D., Kulagin V.A., Shokin Yu.I., Lee F.-Ch. Heat and mass transfer and supercavitation. Novosibirsk: Nauka, 2015. 436 p. (in Russian)].

[23] Демиденко Н.Д., Кулагин В.А., Шокин Ю.И. Моделирование и вычислительные технологии распределенных систем. Новосибирск: Наука, 2012. 424 с. [Demidenko N.D., Kulagin V. A., Shokin Yu.I. Modeling and computing technologies of distributed systems. Novosibirsk: Nauka, 2012.424 p. (in Russian)].

[24] Kulagina T.A., Troshkin, O. A. Improvements in the ecological safety of thermal process plants on conversion to a water-carbon fuel, Chem Petrol Eng, 2006, 42, 367-371.

[25] Борзов А.И., Баранова М.П. Получение стабильных водоугольных суспензий из углей Черемховского месторождения, Химия твердого топлива, 1996, 1, 32-35 [Borzov A.I., Baranova M.P. Obtaining stable coal-water suspensions from coals of the Cheremkhovskoye deposit, Chemistry of Solid Fuel, 1996, 1, 32-35 (inRussian)].

[26] Горлов Е.Г., Головин Г.С., Зотова О. В. Усовершенствование технологии создания водоугольного топлива из бурых углей, Химия твердого топлива, 1994, 6, 117-125 [Gorlov E. G., Golovin G.S., Zotova O.V. improvement of the technology of creatingcoal-water fuel from brown coal, Chemistry of Solid Fuel, 1994, 6, 117-125 (in Russian)].

[27] Горлов Е.Г., Быковский В. Б., Вартанова А. А. и др. Экологические проблемы производства водоугольных суспензий из бурых углей Канско-Ачинского бассейна, Химия твердого топлива, 1998, 2, 64-74 [Gorlov E. G., Bykovsky V.B., Vartanova A. A. et al. Environmental problems of the production of coal-water suspensions from brown coals of the Kansk-Achinsk basin, Chemistry of Solid Fuel, 1998, 2, 64-74 (in Russian)].

[28] Дегтяренко Т.Д., Завгородний В.А., Макаров А.С., Гамера А. В. Особенности получения высококонцентрированных водоугольных суспензий из малозольных углей, Химия твердого топлива, 1989, 5, 99-102 (in Russian).

[29] Дегтяренко Т.Д., Завгородний В.А., Васильева В.В., Макаров А.С. Свойства высококонцентрированных водоугольных суспензий с добавкой лигносульфата и щелочного компонента, Химия твердого топлива, 1988, 3, 81-85 [Degtyarenko T.D., Zavgorodniy V.A.,

$$
-501-
$$


Makarov A. S., Gamera A. V. Features of obtaining highly concentrated coal-water suspensions from low - ashcoals, Chemistry of Solid Fuel, 1989, 5, 99-102. (in Russian)].

[30] Делягин Г.Н., Петраков А.П., Головин Г. С., Горлов Е.Г. Водные дисперсные системы на основе бурых углей как энергетическое и технологическое топливо, Российский химический журнал, 1997, 6, 72-77 [Delyagin G.N., Petrakov A.P., Golovin G. S., Gorlov E. G. Aqueous Dispersed Systems Basedon Brown Coalsas Energy and Technological Fuel, Russian Chemical Journal, 1997, 6, 72-77 (in Russian)]

[31] Делягин Г.Н., Каган Я.М., Кондратьев А.С. Жидкое топливо на основе угольных суспензий: возможности и перспективы использования, Российский химический журнал, 1994, 3, 22-27 [Delyagin GN, Kagan Ya.M., Kondrat'ev A. S. Liquid fuel based on coal suspensions: possibilities and prospects of use, Russian Chemical Journal, 1994, 3, $22-27$ (in Russian)].

[32] Демидов Ю.В., Бруер Г.Г., Колесников С. М. Получение высококонцентрированных водоугольных суспензий из бурых углей Канско-Ачинского бассейна, Экономика угольной промышленности, 1995, 1, 20-22 [Demidov Yu.V., Bruer G. G., Kolesnikov S. M. Obtaining highly concentrated Coal - water suspensions from browncoals of the Kansk-Achinsk basin, Economics of the coal industry, 1995, 1, 20-22 (in Russian)].

[33] Демидов Ю.В., Бруер Г. Г., Колесников С. М. Улучшенный состав твердого топлива для водоугольной суспензии на основе бурых углей Канско-Ачинского бассейна, Химия твердого топлива, 1995, 5, 3-6 [Demidov Yu.V., Bruer G. G., Kolesnikov S. M. Improved composition of solid fuel for coal - water suspension base donbrown coals of the Kansk-Achinsk basin, Chemistry of Solid Fuel, 1995, 5, 3-6 (in Russian)].

[34] Евтушенко Е.А., Нохдренко Г. В., Овчинников Ю. В. и др. Новая технология использования твердого топлива в энергетике, Экология энергетики-2000: Материалы Международной научн.-практ. конф, 2000, с. 303-305 [Evtushenko E. A., Nokhdrenko G. V., Ovchinnikov Yu.V. et al. New technology for the use of solid fuel in power engineering, Ecology of power engineering-2000: Proceedings of the International scientific-practical. Conf, 2000, 303-305 (in Russian)].

[35] Елишевич А.Т., Корженевская Н. Г., Самойлик В. Г., Хилько С. Л. Исследование влияния содержания минеральных примесей на реологические свойства водоугольных суспензий, Химия твердого топлива, 1988, 5, 130-133 [Elishevich A. T., Korzhenevskaya N. G., Samoilik V. G., Khilko S.L. Investigation of the influence of the content of mineral impurities on the rheological properties of coal-water suspensions, Chemistry of Solid Fuel, 1988, 5, 130-133 (in Russian)].

[36] Zaostrovskii, A.N., Sarychev, V.D., Umanskii, A.A. et al. Thermal analysis of coal and water-coal suspensions, Coke Chem., 2012, 55, 10-14.

[37] Клобертанц А.Я., Черкасов А.Т. О проектных решениях и опыте внедрения систем сжигания водоугольного топлива на Новосибирской ТЭЦ-5, Энергетическое cтроительство, 1995, 2, 43-46 [Klobertants A. Ya., Cherkasov A. T. On design solutions and the experience of introducing coal-water fuel combustion systems at Novosibirskaya CHPP-5, Energeticheskoe stroitel'stvo, 1995, 2, 43-46 (in Russian)].

[38] Колесников С.М., Владимирцева И.И., Баранова М.П. О седиментационной устойчивости буроугольных суспензий, Уголь, 1994, 2, 60-61 [Kolesnikov S.M., Vladimirtseva I.I., Baranova M.P. On sedimentation stability of brown coal suspensions, Ugol', 1994, 2, 60-61 (in Russian)]. 
[39] Корженевская Н.Г., Хилько С. Л. Состав водной фазы водоугольной суспензии при различных значениях рН, Химия твердого топлива, 1989, 5, 109-113 [Korzhenevskaya N.G., Khilko S.L. Composition of the aqueous phase of a coal-water suspension at different $\mathrm{pH}$ values, Chemistry of Solid Fuel, 1989, 5, 109-113 (in Russian)].

[40] Корочкин Г.К., Мурко В.И., Своров В.А. Сырьевая база для приготовления высококонцентрированных водоугольных суспензий применительно к углепроводу Белово-Новосибирск, Химия твердого топлива, 2000, 3, 83-89 [Korochkin G. K., Murko V.I., Svorov V.A. Raw material base for the preparation of highly concentrated coal-water suspensions as applied to the Belovo-Novosibirsk coal pipeline, Chemistry Solid Fuel, 2000, 3, 83-89 (in Russian)].

[41] Нехороший И.Х. Использование мазутоугольных и водоугольныых суспензий в энергетике Японии, Теплоэнергетика, 1991, 8, 73-75 [Nekhoroshy I. Kh. The use of fuel oil and coal - water suspensions in the power engineering of Japan, Teploenergetika, 1991, 8, 73-75 (in Russian)].

[42] Нехороший И.Х., Костовецкий С. П., Мурко В. И. и др. Результаты перевода котла КВTC-20 на сжигание водоугольного топлива, Теплоэнергетика, 1997, 2, 13-15 [Nekhoroshy I. Kh., Kostovetsky S.P., Murko V.I. et al. Results of the conversion of the KV-TS-20 boiler to the combustion of water-coal fuel, Teploenergetika, 1997, 2, 13-15 (in Russian)].

[43] Попов В.И., Коваленко Ю. А., Борисов А.А. Реологические и теплофизические свойства водоугольных суспензий, Теплоэнергетика, 1995, 8, 39-43 [Popov V.I., Kovalenko Yu.A., Borisov A. A. Rheological and thermophysical properties of coal-water suspensions, Teploenergetika, 1995, 8, 39-43 (in Russian)].

[44] Саламатин А.Г. О состоянии и перспективах использования водоугольного топлива в России, Уголь, 2000, 3, 10-15 [Salamatin A. G. On the state and prospects of using coal-water fuel in Russia, Ugol, 2000, 3, 10-15 (in Russian)].

[45] Серант Ф.А., Цепенок А. И., Овчинников Ю. В., Луценко С. В., Карпов Е. Г. Приготовление водоугольного топлива и технологии его сжигания, Современная наука, 2011, 6, 95-101 [Serant F. A., Tsepenok A. I., Ovchinnikov Yu.V., Lutsenko S. V., Karpov E. G. Preparation of coalwater fuel and technologies for its combustion, Modern science, 2011, 6, 95-101 (in Russian)].

[46] Хидиятов А.М., Бабий Б.И., Осинцев В.В. и др. Основные результаты исследований водоугольного топлива и перспективы его использования, Развитие технологий подготовки и сжигания топлива на электростанциях: Сборник научных статей ВТИ, 1996, 123-141 [Khidiyatov A. M., Babiy B.I., Osintsev V.V. and others. The main results of research on coal-water fuel and prospects for its use, Development of technologies for the preparation and combustion of fuel at power plants: Collection of scientific articles VTI, 1996, 123-141 (in Russian)].

[47] Хидиятов, А.М., Осинцев В.В., Дубовцев Л.И. и др. Перспективы, основные результаты исследований и проблемы использования водоугольных суспензий в энергетике, Электрические станции, 1988, 9, 2-12 [Khidiyatov, A.M., Osintsev V.V., Dubovtsev L. I. et al. Prospects, main research results and problems of using coal-water suspensions in power engineering, Electric stations, 1988, 9, pp. 2-12 (in Russian)].

[48] Хидиятов А.М., Осинцев В. В., Гордеев С. В. и др. Результаты перевода пылеугольного котла паропроизводительностью 89 кг/с на сжигание водоугольной суспензии, Теплоэнергетика, 1987, 1, 6-11 [Khidiyatov A.M., Osintsev V. V., Gordeev S. V. et al. Results of transferring 
a pulverized coal boiler with a steam capacity of $89 \mathrm{~kg} / \mathrm{s}$ to combustion of a coal-water suspension, Teploenergetika, 1987, 1, 6-11 (in Russian)].

[49] Шорохов В.П., Бруер Г.Г. Высококонцентрированные угольные суспензии - новое топливо для электростанций, Электрические станции, 1992, 11, 33-39 [Shorokhov V.P., Bruer G. G. Highly concentrated coal suspensions - a new fuel for power plants, Electric stations, 1992, 11, 33-39 (in Russian)].

[50] Dunn-Ranbin, Hoorustra J., Cruelich F. A., Holve D. J. Combustion of coal-water slurries, Fuel, 1994, 66, 1137-1145.

[51] Farris R.J. Prediction of the viscosity of miltimodal suspensions from unimodal viscosity data, Trans. Soc. Rheol, 1968, 12(2), 281-301.

[52] Grinzi F.D., Romani G., Grinzi F., Ercolani Snamprogetti reocarb: from the production plants into the boilers. Proc. 8-th Int. Symp. on Coal Slurry Fuels Preparation and Utilization, 1986. 947-951.

[53] Hammond T.K., Mathiesen M. M. Manufacture and commercial use of carbogel coal/water fuel in Canada 6th Jnt. Symp. Coal Slurry Combust and Technol, 1984, 982-989.

[54] Klose R.B. DENSECOAL - an alternative to gas and oil, 6-th Jnt. Symp. On Coal Slury Combust and Technol., 1984, 791-805.

[55] Landry G. The Cape Breton Development Corporation's Carbogel Coal Water Fuel Project, Proc. 7-th Int. Symp. on Coal Slurry Fuel Preparation and Utilization, 1985, 1001-1013.

[56] Linder G., Rogren B., Linder G. Start-up and operating experience of three commercial CWM contractis in Sweden, Proc. 8-th Int. Symp. on Coal Slurry Fuel Preparation and Utilization, 1986, 933-946.

[57] Schwarz O. Das Entwicklugsvorhaben Directe Verbrennung von Kohle-Wasser-Suspension in Kraftwerken, Electrizi-tatwirtschaft, 1966, 719-723.

[58] Schwarz O. Verbrennung von Staubkohle und Kohle-Wasser-Suspension in Wasserrohrkesseln, Brennst - Warme-Kraft, 1964, 16. 273-277.

[59] Skvara F., Vancurova M., Skvara F. The effect of particle size distruction on apparent viscosity of dispersion system, Silikaty, 1973, 1, 10-20.

[60] Gvozdyakov, D.V., Gubin, V.E., Larionov, K.B. et al. Ignition of Coal-Water Fuel with the Addition of the Liquid Fraction of Rubber Pyrolysis Products, Chem Petrol Eng, 2020, 56, 42-47.

[61] Glushkov D.O., Feoktistov D. V., Kuznetsov G. V., Batishcheva K.A., Kudelova T., Paushkina K.K., Conditions and characteristics of droplets breakup for industrial waste-derived fuel suspensions ignited in high-temperature air, Fuel, 2020, 265, 116915.

[62] Kuznetsov G.V., Nyashina G.S., Valiullin T.R. et al. Benefits of Slurry Fuels Based on Industrial Wastes. Coke Chem., 2019, 62, 422-432.

[63] Valiullin, T.R., Vershinina, K.Y., Lyrshchikov, S.Y. et al. Regimes of the Combustion of Organic Coal-Water Fuels, Solid Fuel Chem., 2018, 52, 78-85.

[64] Nyashina, G.S., Kurgankina, M.A., Akhmetshin, M.R. et al. Ash Composition in the Combustion of Promising Slurry Fuels, Coke Chem., 2020, 63, 149-158.

[65] Lyrshchikov, S.Y., Strizhak, P.A. \& Shevyrev, S.A. Ash residue from droplets of organic coal-water fuels burned at different oxidant temperatures. Coke Chem., 2016, 59, 178-185.

[66] Glushkov, D.O., Strizhak, P.A. \& Chernetskii, M. Y. Organic coal-water fuel: Problems and advances (Review), Therm. Eng, 2016, 63, 707-717. 
[67] Vershinina, K.Y., Strizhak, P. A. Ignition of coal suspensions based on water of different quality, Coke Chem., 2016, 59, 437-440.

[68] Valiullin, T.R., Vershinina, K.Y., Glushkov, D.O. et al. Droplet ignition of coal-water slurries prepared from typical coal- and oil-processing wastes, Coke Chem., 2017, 60,211-218.

[69] Vershinina, K.Y., Glushkov, D.O. \& Strizhak, P. A. Ignition of droplets of coal-water-oil mixtures based on coke and semicoke, Coke Chem., 2017, 60, 28-36.

[70] Red'kina, N.I., Khodakov, G.S. \& Gorlov, E. G. Coal fuel slurry for internal combustion engines, Solid Fuel Chem., 2013, 47, 306-314.

[71] Murko V.I., Karpenok V. I., Fedyaev V.T., Silyutin S. A. The development of a technological complex for utilization of finew Waste coal PP «Tugnuyskaya», XVIII International Coal Preparation Congress, 2016, 339-343.

[72] Wang H., Jiang X.-M., Shen L.-L.. Fluidization-suspension combustion technology of coal water slurry and design of a 14 MW horizontal boiler, Journal of the China Coal Society, 2008, 33(7), 789-793.

[73] Hui W., Xiumin J., Minxiao Zh., Yufeng M., Hui L., Shaohua Wu. A new fluidizationsuspension combustion technology for coal water slurry, Chemical Engineering and Processing: Process Intensification, 2010, 49(10), 1017-1024.

[74] Горлов Е.Г., Андриенко В.Г., Нефёдов К.Б., Луценко С. В., Нефёдов Б. К. Прямоточная газификация водоугольных суспензий с сухим шлакообразованием высокозольных углей, Xuмия твердого топлива, 2009, 2, 37-42 [Gorlov E. G., Andrienko V. G., Nefedov K. B., Lutsenko S. V., Nefedov B.K. Direct-flow gasification of coal-water suspensions with dry slagging of high-ash coals, Chemistry of Solid Fuel, 2009, 2, 37-42 (in Russian)].

[75] Мингалеева Г.Р. Определение оптимальных характеристик водоугольного топлива по условиям транспортирования и газификации, VIII Всероссийская конференция с международным участием «Горение твердого топлива», 2012, 65.1-65.4 [Mingaleeva G. R. Determination of the optimal characteristics of coal-water fuel in terms of transportation and gasification, VIII AllRussian conference with international participation «Solid fuel combustion», 2012, 65.1-65.4 (in Russian)].

[76] Шпирт М.Я., Горюнова Н.П. Утилизация твердых отходов, образующихся при газификации водоугольных суспензий в прямоточном газогенераторе, Химия твердого топлива, 2009, 4, 53-59 [Shpirt M. Ya., Goryunova N.P. Disposal of solid waste generated during gasification of coalwater suspensions in a co-current gas generator, Chemistry Solid Fuel, 2009, 4, 53-59 (in Russian)].

[77] Потапов Б. Б., Пинчук В.А. Исследование и разработка режимов поточной газификации углей украинских месторождений, Современная наука, 2010, 3 (5), 92-97 [Potapov B.В., Pinchuk V. A. Sovremennaya nauka, 2010, 3(5), 92-97 (in Russian)].

[78] Пинчук В.А., Шарабура Т.А., Потапов Б. Б. Особенности газификации водоугольного топлива в газификаторах циклонного типа, Інтегровані технології та енергозбереження, 2009, 2, 131-133 [Pinchuk V. A., Sharabura T. A., Potapov B. B. Features of gasification of coal-water fuel in cyclone-type gasifiers, Integrated technologies and energozberezhennya, 2009, 2, 131-133 (in Russian)].

[79] Галькеева А.А. Разработка энергоэффективного и ресурсосберегающего способа газификации водоугольного топлива, автореф. дисс. ... канд. техн. наук, Казань, 2019, 16 с. 
[Galkeeva A. A. Development of an energy-efficient and resource-saving method for gasification of coal-water fuel, Author. ... cand. tech. nauk, Kazan, 2019, 16 p. (in Russian)].

[80] Зайцев А.С., Егоров Р.И., Ткаченко П.П., Белоногов М.В. Газификация водоугольных композиций лазерными импульсами различной интенсивности, Химия твердого топлива, 2019, 1, 54-60 [Zaitsev A. S., Egorov R. I., Tkachenko P. P., Belonogov M. V. Gasificationofcoalwatercompositionsbylaserpulsesofvariousintensities, Chemistry of Solid Fuel, 2019, 1, 54-60 (in Russian)].

[81] Тимофеева С.С., Мингалеева Г.Р. Технологическая схема автономной энергоустановки с газификацией водоугольного топлива, Сб. материалов ХХІІІ Всероссийской межвузовской научно-технической конференции «Электромеханические и внутрикамерные процессы в энергетических установках, струйная акустика и диагностика, приборы и методы контроля окружающей среды, веществ, материалов и изделий», 2011, 123-124 [Timofeeva S. S., Mingaleeva G.R. Technological diagram of an autonomous power plant withgasification coalwaterfuel, Sat. materials of the XXIII All-Russian interuniversity scientific and technical conference «Electromechanical and intra-chamber processes in power plants, jetacousticsand diagnostics, instruments and methods for monitoring the environment, substances, materials and products», 2011, 123-124 (in Russian)].

[82] Горлов Е.Г., Андриенко В. Г., Нефёдов К. Б., Луценко С. В., Нефёдов Б. К. Прямоточная газификация водоугольных суспензий с сухим шлакообразованием высокозольных углей, $X u$ мия твердого топлива, 2009, 2, 37-42 [Gorlov E. G., Andrienko V. G., Nefedov K. B., Lutsenko S. V., Nefedov B. K. Direct-flow gasification of coal-water suspensions with dry slagging of high-ash coals, Chemistry of Solid Fuel, 2009, 2, 37-42 (in Russian)].

[83]. Пинчук В.А., Жуков В.Е., Шарабура Т.А. Экспериментальные исследования теплопроводности водоугольных суспензий. Сборник научных статей: Современная наука: исследования, идеи, результаты, технологии. Киев: «НПВК Триакон», 2013. Вып. 2(13). 149155 [Pinchuk V.A., Zhukov V.E., Sharabura T.A. Experimental studies of thermal conductivity of coal-water suspensions. Collection of scientific articles: Modern science: research, ideas, results, technologies. Kiev: «NPVK Triakon», 2013. Iss. 2(13) 149-155(inRussian)].

[84]. Деди Л., Цзиньцянь В. и др. Экспериментальные исследования угольных водных суспензий, приготовленных из сточных вод газификации угля, Азиатско-Тихоокеанский журнал химического машиностроения, 2017, 13(1) [Dedi L., Jianzhong L., Jinqian V. et al, Experimental studies of coal aqueous suspensions prepared from wastewater from coal gasification, Asia-Pacific Journal of Chemical Engineering, 2017, 13(1) (in Russian)]. 